Yayınlayan: Ankara Üniversitesi KASAUM

Adres: Kadın Sorunları Araştırma ve Uygulama Merkezi, Cebeci 06590 Ankara

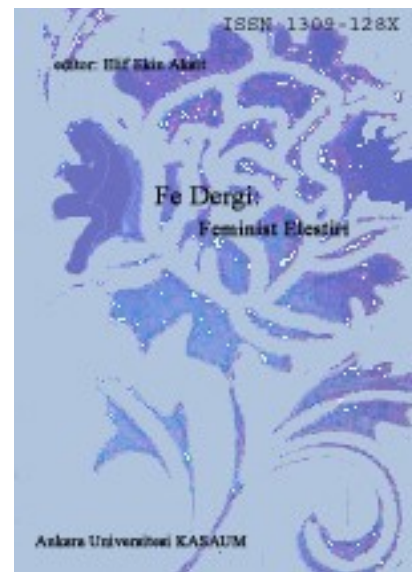

Fe Dergi: Feminist Eleştiri 5, Sayı 2

Erişim bilgileri, makale sunumu ve ayrıntılar için:

http://cins.ankara.edu.tr/

Zorla Güzellik: Recep İvedik Serisinde Bedensel

Güzellik ve Çirkinlik

Dilara Güryuva

Çevrimiçi yayına başlama tarihi: 24 Aralık 2013

Bu makaleyi alıntılamak için: Dilara Güryuva, "Zorla Güzellik: Recep İvedik Serisinde Bedensel Güzellik ve Çirkinlik" Fe Dergi 5, no. 2 (2013), 108-119.

URL: http://cins.ankara.edu.tr/10_13.html

$\mathrm{Bu}$ eser akademik faaliyetlerde ve referans verilerek kullanılabilir. Hiçbir şekilde izin alınmaksızın çoğaltılamaz. 


\section{Zorla Güzellik: Recep İvedik Serisinde Bedensel Güzellik ve Çirkinlik Dilara Güryuva*}

Bu çalışmanın amacı Batı merkezli kapitalist ekonomi ve toplumsal cinsiyet kalıpları tarafindan şekillendirilmiş yaygın güzellik idealinin ve bu idealin sınırlarını çizen çirkinlik olgusunun, çok sayıda izleyiciye ulaşmış bir güldürü olan Recep İvedik serisinde nasıl ele alındığını ortaya koymaktır. Bu amaçla yapılan içerik analizi, filmin bedensel çirkinliği gülünç ilan edip yererek norm dışına ittiğini; bedensel güzelliği ise prestij ve başarı gibi yan anlamları ile ilişki içinde sunduğunu ortaya koymaktadır. Recep İvedik serisi, bir kadının ve bir erkeğin nasıl görünmesi gerektiğini belirleyen yaygın güzellik idealini destekleyen bir anlatıdır.

\section{Anahtar Sözcüler: Popüler Sinema, Komedi, Recep İvedik, Güzellik, Çirkinlik}

\section{Beauty as Necessity: Psysical Beautyand Ugliness in Recep İvedik}

The purpose of this study is tracking the representation of psycial beauty and ugliness which determined by western centered capitalist economy and gender in Recep Ivedik movies. Content analysis for this purpose shows that the movies represents ugliness as something funny and horrifying and pushing ugliness out of norms. Correspondingly, the representation of beauty shows that the beauty is associated with positive connotations like prestige and sucsess which codes beauty as normal. In this work, it's argued that Recep Ivedik movies supports the common beatuy ideal which determines how a women or men should look like.

Keywords: Popular Cinema, Comedy, Recep Ivedik, Beauty, Ugliness

\section{Giriş}

İlk filmi 2008 yılında vizyona giren Recep İvedik serisi, gerek sinemada ulaştığı izleyici kitlesinin genişliği, gerek ortaya koyduğu sıra dışı maganda tiplemesi, gerekse sinema dilini kullanış biçimiyle birçok tartışmanın konusu olmuştur. Antropomorfik bir sanat dalı olan sinemada ve özellikle fiziksel komedi eğilimi gösteren karakter komedisinde ${ }^{1}$ insan bedeninin kullanımı da önemli bir konudur. İnsan bedeninin nasıl görünmesi gerektiği, mekansal olarak nerelerde bulunabileceği, hangi biçimleri alabileceği gibi konular bireyin tercihlerinden ziyade toplumsal olarak belirlenir ve Foucaultçu anlamda iktidar ilişkilerinde içkindir. ${ }^{2}$ Amaçları ve vaadleri gereği toplumun değer yargıları ile çelişmeme eğiliminde olan popüler sinema, bu toplumsal beden kurgusunun izlerinin sürülebileceği bir araştırma alanı oluşturmaktadır.

\section{Yaygın Güzellik İdeali}

$\mathrm{Bu}$ gün kitle iletişim araçlarında bedenin görünümüne atfedilen anlamların en baskını güzellik ve çirkinlik merkezli bir ideal beden kurgusudur. Söz konusu ideal beden kurgusu büyük ölçüde tüketim toplumu ve bununla ilişkili halindeki toplumsal cinsiyet ile ilintilidir. Bu gün tüketim toplumuna entegre olan Türkiye'de bedensel güzellik ve çirkinlik de tüketim toplumunun normlarına göre belirlenmektedir. Baudrillard'a göre, tüketim nesnelerinin işlev alanları dışında, gösterge değerinin kazandırdığı yan anlamlar ile alıcı bulduğ ${ }^{3}$ tüketim toplumunda insan bedeni de hem sermaye hem tüketim nesnesi olarak işlev görür. ${ }^{4}$ Yazara göre beden yani sermaye özen gösterme yolu ile değerli kılınır ve değişim değeri (prestij, cinsellik) üzerinden gösterge değiş tokuşunda kullanılır. Bu kurgunun anlam kazandığı nokta ise şudur: "Beden sattırır" Yani artık ne dinsel görüşteki gibi et, ne de sanayisel mantıktaki gibi emek gücü olan beden, uzun bir kutsallaştırma sürecinin sonunda nasristik bir kült nesnesi halini almıştır. ${ }^{5}$ Bu dönüşümün merkezindeki aktör ise potansiyel olarak sınırsız üretim olanağına kavuşmuş, buna koşut olarak bu kez de talebi arttırmanın peşine düşmüş olan çağdaş kapitalizmdir. ${ }^{6}$

Bedeni değerli, yani cinsel açıdan arzulanır, seyredilir, hayranlık uyandırır bir biçime sokmanın çağın gereksinimi olduğu düşüncesi 1980 'lerden itibaren, serbest piyasa ekonomisinin gelişimine paralel biçimde

\footnotetext{
*Ankara Üniversitesi Sosyal Bilimler Enstitüsü, Radyo Televizyon ve Sinema Bölümü Yüksek Lisans Mezunu
} 
ülkemizde de yaygın bir söylem haline gelmiştir. Kalorisi azaltılmış, light ürünlerin piyasaya sürülmesi, fitness ve aerobiğin televizyon ve basılı yayınlarda toplumsal statü göstergesi olarak sunulması ve kadın güzelliğinin normlarını belirleyip önemine vurgu yapan Kadınca ve Elele gibi dergilerin raflarda yer almaya başlaması yine aynı yıllara tekabül etmektedir." "Birçok şeyin gösterildiği için, sergilendiği ve seyredildiği kadar değer kazandığ1" ${ }^{8}$ bu dönemde bedenin görümü de önem kazanmış, güzel bir görünüm başarı, beğeni ve prestijin kaynağı haline gelmiştir. 2001 krizinin atlatılmasının ardından hayat artık tüketmek, tüketmek ise var olmak anlamına gelmeye başlamış, ${ }^{9}$ tüketim toplumunun bedensel güzelliğe biçtiği anlamlar de sabitleşmiştir.

Tek tip ve ulaşılması zor bir güzellik idealinin bireyin ödevi haline gelmesi, o ideale ulaşabilmek adına tüketmesi anlamına gelir. Kişinin gögüslerine silikon taktırmak için öncelikle gögüslerinin daha büyük olması gerektiğine inanması gerekir. Fondoten satın alıp kullanmak içinse cildin pürüzsüz görünmesi gerektiğini düşünmek ön koşuldur. Hedef ulaşılması zor bir hal aldıkça tüketim de canlı kalmaktadır. Bu gün, şişman olmamanın yeterli olduğu günler geride kalmış, 90-60-90 ölçülerindeki beden ideali de yerini orta boylu bir kadında 32 bedene tekabül eden "sıfır beden" söylemine bırakmıştır. On beş yıl önce adı bile bilmeyen selülit bu gün bir kusur ilan edilmiş ${ }^{10}$ ve selülitten kurtulmak için satın alınabilecek çok sayıda ürün piyasaya sürülmüştür. 2010 yılı itibarı ile dünya çapında 200 milyar dolar, Türkiye'de ise 1,5 milyar Euro'luk hacmi olan kozmetik sektörü, ${ }^{11}$ varlığını büyük ölçüde insanların bedenlerinden duyduğu hoşnutsuzluğa borçludur.

Bireylerin bedenlerinden hoşnutsuz olmaları özgüvensizlik, depresyon, hatta ölümcül sonuçlara yol açan yeme bozukluklarına zemin hazırlamaktadır. Yapılan araştırmalar bedeninden hoşnut olmayan erkekler ile bedeninden hoşnut olmayan kadınlar arasında belirgin bir oran farkı olmadığını göstermektedir. ${ }^{12}$ Ancak bedeninden hoşnut olmayan kadınlarda depresyon ${ }^{13}$ ve yemek bozukluğu görülme oranı erkeklerde görülme oranından daha yüksektir. ${ }^{14}$ Güzel görünme buyruğunun kadınlar üzerinde daha ciddi bir baskı oluşturmasını ise toplumsal cinsiyet ile açıklamak mümkündür.

Toplumsal cinsiyetin akıl ile özdeşleştirdiği erkek ruh, doğa ile özdeşleştirdiği kadın ise bedendir. ${ }^{15}$ Bordo'ya göre bu cinsiyetlendirilmiş beden-ruh ikiliği gündelik hayatın mitolojisini öylesine etkilemektedir ki kadınına atfedilen kimi olumsuz anlamların ortaya çıkmasında etkilidir. Batı kültüründe beden dikkati bilginin alanından uzağa çeken, kişiyi cinsel arzuya teslim eden, iradenin çökmesinden sorumlu olan, ruha hapishane olan pasif, maddesel bir varlık olarak negatif anlamların taşıyıcısıdır. Tersine erkek ile özdeşleştirilen ruh motive edici ve eyleme yöneltici olmak gibi pozitif anlamların taşıyıcısıdır. ${ }^{16}$ Kadınlığın beden, erkekliğin ruh ile anlamlandırıldığı bu kurguda kadının bedeni ve erkek bedenine atfedilen önemin farklı olması da şaşırtıcı değildir. Başka bir değişle "erkeğin güç ve başarısı, kadının ise çekicilik ve arzulanırlığı ile değer gördüğü toplumlarda kadınların beden imajı erkeklerinkinden daha çok tasa konusu haline gelmektedir." ${ }^{17}$ Güzel olmak, kadına atfedilen anlamların önemli bir parçasını oluşturmaktadır ve "ona müreffeh bir evlilik sağlayacak olan iyi bir evliliğin anahtarlarındandır." ${ }^{18}$ Heteronormatif aile kurgusuyla ilişkisinin yanı sıra, kadının seyredilen konumunda olması da bu baskıyı arttıran nedenlerden bir tanesidir. Kadının ikincil ve öteki konumu, onun bedenini yargılanan, denetlenen bir beden haline sokar. ${ }^{19}$ Öyle ki küçüklüğünden beri kendini gözetim altında tutması öğretilen kadın kendi kendini ve başkaları tarafından seyredilişini seyreder; böylece görsel, seyirlik bir nesneye dönüşür. ${ }^{20}$ Böylece kadın bedeninin görünümü erkek bedeninin görünümünden daha önemli bir mesele haline gelir.

Yaygın güzellik idealine uygun bir bedene sahip olma zorunluluğunun kadınlar üzerinde daha ciddi bir baskı oluşturması, erkeklerin bu zorunluluktan azade olduğu anlamına gelmemektedir. Hem kadınlar hem erkekler için uyulması gereken belirli kriterler vardır. Bunlardan ilki formda bir bedene sahip olmaktır. Şişmanlık püriten ahlakın ortaya çıkmasından bu yana hiç bir zaman hoş görülmemiş, tembellik ve dirayetsizlik ile ilişkilendirilmiştir. ${ }^{21}$ Yaratılan vücut idealine ilgili korumak adına önemli mekanizmalardan bir tanesi şişmanlık ve ete yönelik bir tiksinti inşa edilmesidir. ${ }^{22}$ Bu tiksinti aynı zamanda şişmanlığı çirkinliğin sınırları içerisine itmektedir. ${ }^{23}$ Yaygın güzellik idealine göre ideal kadın bedeni incecik, bir dirhem bile fazla eti bulunmayan, zerafet, narinlik ve kibarlığı çağrıştıran bir bedendir. Şişmanlık aynı zamanda kadına biçilen fedakarlık rolüyle de uyumsuzdur. Kadının görevi başkalarına bakmak, kendisini değil başkalarını beslemektir; zira "erkek yer kadın hazırlar."24 Yemeğe düşkünlük ise haz arayışıdır. Böylece yaygın güzellik idealinin övdüğü kadın bedeni, geleneksel kadınlık rolü ile bütünlüklü bir manzara ortaya koyar, bir kadının nasıl görünmesi gerektiğini belirler.

Kadının olabildiğince ince olmasını öngören yaygın güzellik ideali, erkeğin ise zayıf fakat iri olmasını destekler. İdeal erkek bedeni güç ve dayanıklılığı çağrıştırır biçimde kaslı ve geniş omuzlu olmalıdır. Erkeklerde sıskalık "oğlanlık"ı çağrıştırmakta, şişmanlık ise akıl ve rasyonalite ilişsilendirilen erkeğin iradesizliği ve 
başarısızlığı halini almaktadır. ${ }^{25}$ Öte yandan Elçik'e göre şişmanlık ve maskülenite arasındaki en ağır taşlardan birini, gögüslerin büyümesi ve penisin bedenin geri kalanına göre küçük kalması oluşturmaktadır. Yazar hem konu ile ilgili yapılan araştırmalara katılan erkek görüşmecilerin ifadelerinde, hem de forum ve sözlük benzeri web sitelerinde, şişmanlığın "penisi görememek" ile ilişkilendirilmesini dikkat çekici bulmuş, penisi görememenin erkeğin erkekliği ile ilgili yaşadığı kuşku ve paniğin sembolik ifadesi olduğunu dile getirmiştir. ${ }^{26}$ Sancar'a göre ise bu ideal erkek bedeni kurgusu yalnız belirli sınıflar için geçerlidir. Endüstriyel kapitalimin kas gücü olarak görüp vücut geliştirme ve he-man imgeleri ile el üstünde tuttuğu beden ideali, işçi sınıfı erkekleri için geçeridir. Erklerini para kazanarak ortaya koyan erkeklerin nasıl göründükleri ise önemini yitirmektedir. ${ }^{27}$

Yaygın güzellik idealinin hem kadınlar hem erkekler için geçerli bir kriteri de gençliktir. Kişinin hangi yaşta olduğundan bağımsız olarak genç görünmesi beklenir. Konuya tüketim toplumu çerçevesinden bakıldığında bunun bedene özen gösterme, yani sermayeyi değerli kılama ile ilişkisi görülebilir. Yaşlanmış beden işlevselliğini, bakılasılığını, cinsel çekiciliğini yitirmiş bedendir. Hem heteroseksüel hem lezbiyen kadınlar arasında yapılan araştırmalar yaşlanma endişesinin her iki grup için de büyük ölçüde çekici bulunmama korkusuna dayandığını göstermektedir. ${ }^{28}$ Aynı söylemin izlerini kadın dergilerinde ve kozmetik reklamlarında görmek de mümkündür. Kozmetik reklamlarında güzelliğin bedende olması gereken ve olmaması gereken özellikler üzerinden kodlandığını dile getiren Oğuz, bedende olmaması gereken özelliklerin yaşlılıkla ortaya çıkan kırışıklık, sarkma, solgunluk gibi unsurlar olduğunu öne sürmektedir. Gençlik ve güzelliği bir arada vaad eden reklamlar, gençliği güzelliğin ayrılmaz bir parçası haline getirir, ${ }^{29}$ güzelliğe yüklenen anlamları gençliğe de yükler. Gençlik bedene gösterilen özenin ödülü olarak güzelliği beraberinde getirirken yaşlılık ise gençleşme yönünde bir çaba harcamamanın cezasıdır. Zira yaşlanmanın önlenebilir, durdurulabilir bir olgu olduğu söylemi reklamlarda ve kadın dergilerinde sıklıkla tekrarlanır.

Yaygın güzellik idealine uyumlu bir beden için şart sayılan üçüncü unsur ise bakımlılıktır. "Giderek yeni orta sınıf kimliğinin göstergesi haline gelen bakımlı beden adeta kişisel gurur ve manevi üstünlük kaynağı olmaktadır. Bunun karşıtı ise yalnız fiziksel değil ahlaki gevşekliğin de göstergesi sayılmaktadır" ${ }^{30} \mathrm{Bu}$ ideale göre kadının saçlarının gür ve parlak, cildinin yumuşak, tırnaklarının manikürlü, kıllarının alınmış ve yüzünün makyajlı olması gerekmektedir. Dizi ve film gibi kurgusal yapitlarda kadın karakterin evde, uyurken, duş alırken bile makyajlı görünmeleri, televizyon programı, internet siteleri ve dergilerde ünlülerin makyajsız görüntülenmelerinin sıra dışı durumlar olarak sunulması, makyaj yapmayı bir norm, yapmamayı ile norm dışı haline getirmektedir. Erkeğin bedenine bakım yapması ise onu metroseksüel ve überseksüel olarak adlandırılan iki farklı erkeklik biçimine dâhil etmektedir. Her iki erkeklik kurgusu da bedene özen göstermeyi ve bakımlı olmayı över. Ancak metroseksüel erkeklik kurgusunda kent yaşamı ve tüketime ayak uydurma ve bu uyum sürecinde kadınsı bulunan nitelikleri de sahiplenmek varken, überseksüel erkeklik kurgusu sisteme uymayı değil kendini ve ihtiyaçlarını bilmeyi öncelikli amaç olarak benimser; bu yolda kimliğini kadınlık ve erkeklikten bağımsız kurar. ${ }^{31} \mathrm{Bu}$ iki erkeklik kurgusunun ortaya çıkması, hegemonik erkeklikte yeri olmayan beden bakımının, kapitalist ekonominin çıkarlarına uygun biçimde erkeklerin de hayatına sokulması biçiminde değerlendirilebilir ancak bu değerlendirme tek başına yeterli değildir. Metroseksüellik ve überseksüellikmodern dönemin erkeklik kurgusunu sürdürmenin zorlaştığı günümüzde, önceki erkeklik kurgusu ile çatışan yeni bir erkeklik biçimi sunmaktadır. Değişen çalışma koşulları, özellikle de post-fordist üretim biçimi, tüketim alışkanlıklarındaki değişme ve kadın hareketinin geleneksel değerlerin dayatması ile mücadelesi, hegemonik erkekliği günün şartlarına ayak uydurabilen daha "esnek" erkeklik biçimlerine dönüşmeye itmiştir. ${ }^{32}$ Dolayısıyla erkeğin bakımlılığı bir norm değil, erkeklik tipleri arasındaki çatışmanın alanında kalan gerilimli bir noktadır. Buna karşın jöle ile saçları şekillendirmek, kepek ve saç dökülmesini önleyici ürünler kullanmak, saç ve sakalı şekillendirmek gibi bakım biçimleri Türk erkekleri arasında sık görülmektedir.

\section{Sinema ve Televizyonda Bedensel Güzellik ve Çirkinlik}

Tüm bu kurgu içerisinde güzel görünmek, kişinin nasıl görünmesi gerektiği ile ilgili normların önemli bir parçasını oluşturmaktadır. Birey "çağın gerekliliği" olarak belirli bir bedensel görünüşe ulaşma baskısı altında kalırken, bu görünüşe sahip olmayanlar da normun dışına itilmektedir. Böylece güzellik ve çirkinlik normalin iki ucunda yer alan durumlar olmaktan çıkmakta ve güzel olmak normal olmak haline gelmektedir. ${ }^{33}$

Featherstone'a göre tüketim kültürünün şekillendirdiği beden algısı geniş bir görsel imaj skalasının varlığı ile üretilip taşınmaktadır. Söz konusu imajların yer aldığı mecralar ise elbette görsel işitsel kitle iletişim araçlarıdır. Yazarın lunaparktaki hileli aynalara benzettiği kameralar deneyimi olduğu gibi değil, başkalaştırarak yansıtmakta, ${ }^{34}$ imajların oluşmasına ve taşınmasına da bu sayede katkıda bulunmaktadır. Sinemadaki yıldız 
olgusu ve stereotipler imaj taşıyıcılığının belirgin örnekleridir. Bunun yanı sıra güzellik ve çirkinliğe dair imajların izlerini, karakterlerin anlatı içinde nasıl konumlandırıldıkları ve diğer karakterden ne gibi tepkiler aldıkları üzerinden de çözümlemek mümkündür.

Güzel karakterlerin aynı zamanda iyi, çirkin karakterlerin ise kötü kişiler olarak kodlandığı stereotipleştirme Hollywood sinemasında uzun zamandır görülen bir olgudur. ${ }^{35}$ Smith, Mcntosh ve Bazzni tarafından gerçekleştirilen alımlama araştırmasının sonuçları, 1950-1990 yılları arasında gösterime giren Hollywood filmlerinde fiziksel açıdan çekici karakterlerin aynı zamanda ahlaki açıdan da iyi, romantik ilişkilerde daha başarılı ve daha mutlu hayatlara sahip karakterler olduğunu ortaya koymuştur. ${ }^{36}$ Televizyon durum komedileri üzerine yapılan bir başka bir araştırmaya göre de ince ve güzel bedenlere sahip kadın karakterler aynı zamanda arzulanan, öz saygısı yüksek ve başarılı karakterlerdir. ${ }^{37}$

Stereotipleştirmenin yanı sıra sıklıkla görülen diğer olgu, karakterlerin bedensel görünüşlerine istinaden sözlü olarak övülmesi ve yerilmesidir. Bir karakterin diğer karakterler tarafindan övülmesini ya da yerilmesi, davranış ve değerlerin öğrenilmesinde en başarılı model olarak kabul edilen cezalandırma ve temsili pekiştirme modeli ile uyuşmaktadır. ${ }^{38}$ Fouts ve Burgaff'ın prime time durum komedilerinde, şişman kadın bedenine yönelik olumsuz yorumları odağına alan araştırması, karakterin kilosu arttıkça maruz kaldığı yerginin de arttığını ortaya koymaktadır. Böylece şişman kadınlar karşısında nasıl bir tavır takınılması gerektiğine yönelik bir norm oluşturulmaktadır. ${ }^{39}$

Söz konusu bir güldürü eseri olduğunda, göz önünde bulundurulması gereken bir diğer olgu da karakterin bedensel görünümünün komik olarak sunulup sunulmadığıdır. İnsan bedeninin hangi hallerinin gülünç kabul edildiği, espri malzemesi yapıldığı, bedenin hangi hallerinin kabul görüp hangi hallerinin kabul görmediği konusunda yol göstericidir. Çünkü gülme (literatürü) kendi içinde tutarlı, yöntemli bir olgu olarak toplumun imgelem gücünün nasıl çalıştı̆̆ını gösterebilir. ${ }^{40} \mathrm{Bu}$ gün halen kabul gören üç gülme kuramına göre komik bularak gülme, ya uyumsuz ${ }^{41}$ olana, ya uygunsuz ${ }^{42}$ olana ya da aşağı görülene ${ }^{43}$ yönelir. Her üç kuramın da ortak noktası gülmenin olumsuz olana yöneldiği kabulüdür. Recep İvedik gibi temel vaadi güldürmek olan bir filmin insan bedeninin görünümüne yaklaşımı, neyi gülünçleştirdiği üzerinden daha net anlaşılacaktır.

\section{Recep İvedik Serisinde Bedensel Güzellik ve Çirkinlik}

Recep İvedik ilki 2008 yılında vizyona girmiş bir karakter komedisi serisidir. Seriye adını veren Recep karakteri Şahan Gökbakar tarafından canlandırılmış, serinin tamamı Togan Gökabakar tarafından yönetilmiştir. Şahan Gökbakar'ın oyunculuğun yanı sıra senaristliği de üstlenmesi, sinemaya hali hazırda sahip olduğu komedyen kimliğiyle geçiş yapması ve serinin yönetmenin ya da yapımcının değil kendisinin adıyla anılması, seriyi bir komedyenin filmi olarak nitelendirmeye olanak sağlamaktadır. Komedyenler ise kanaat önderleridir. Öyle ki Amerika'da komedyenler giderek daha çok put y1kan ve doğruyu söylen kişiler olarak görülmeye, politikacılardan daha güvenilir kabul edilemeye başlamıştır. ${ }^{44}$

Tüketim kültürünün temellerinin atıldı̆̆ı, endüstrinin hayatta kalmasına yönelik agresif bir strateji olarak tüketimciliğin "eğitme" ve "manüpilasyon" ile yayılmasının amaçlandığı 1920'li yıllardan beri yıldız olgusu, tüketimciliğe yönelik norm ve davranış kalıplarının oluşmasında önemli akörlerden bir tanesi olmuştur. ${ }^{45}$ Oysa günümüz Türk sinemasında yıldız oyuncu denilince akla gelen isimlerin sayısı oldukça azdır. Akla gelen isimler ise üzerinde uzlaşılmış biçimde yıldız kabul edilmemektedir. Bu ortam içinde Recep İvedik'i canlandıran Şahan Gökbakar'ın belli bir boşluğu tamamladığını söylemek mümkündür. Komedyenler yıldızların yerini tutamasa da yıldız olgusunun karşıladığı bir takım ihtiyaçlara cevap vermektedir. McDonald'a göre yıldız olgusunun çok katmanlı bir niteliği vardır. Olgunun bir yüzünde "varlıklı, göz kamaştırıcı ve güzel insanlar" dedirten genel bir algı, öbür yüzünde ise yıldızlara tekil olarak işaret eden otantik kimlikler vardır. ${ }^{46}$ Yıldızların varlıklı, göz kamaştırıcı ve güzel olmaları, ulaşılmak istenen ideal durumun prototipi olarak toplum gözünde onaylanmış bir model olmalarını sağlar. ${ }^{47}$ Yıldızın otantik kimlikleri ve bu kimliklerin cevap verdiği ihtiyaçlar ${ }^{48}$ komedyenler tarafından hali hazırda ikame edilmektedir. Eksik kalan unsur fiziksel çekiciliğe dayanan bir karizma ile ideal durumun prototipi olmamalarıdır. Şahan Gökbakar'ın ilk üç filmi olan Recep İvedik Serisi ile oluşturduğu, televizyon reklamları ve viral videolar ile desteklediği persona ise ideal durumun değil, tam aksine olmaması gerekenin prototipini net bir biçimde ortaya koymaktadır. Dolayısıyla yıldızların görünürlüklerinin düşük olduğu günümüz Türk sinemasında Şahan Gökbakar'ın, tüketim kültüründe yıldız olgusunun yerini tam tersi bir yönden doldurduğunu söylemek yanlış olmayacaktır.

Seri, Güngören'de yaşayan, 35 yaşında, düşük sosyo-ekonomik statüye mensup bir maganda olan Recep İvedik'in, "Beyaz Türkler"in dünyasındaki maceralarını anlatmaktadır. Karakter 2008 yılında vizyona 
giren ilk filmde yaptığı iyiliğe karşılık olarak bir tatil köyünde misafir edilir. 2009 yılında vizyona giren ikinci filmde iş bulmak, saygınlık kazanmak ve evlenmek maksadıyla daha önce bulunmadığı ortamlara girer. Serinin 2010 yılında vizyona giren son filminde ise karakterin depresyonunu yenmek için farklı hobiler ve sosyal ortamlar arasında gezinmesi anlatılır. Seri kronolojik bir sıra izlemeyen, birbirinden bağımsız filmlerden oluşsa da Recep'in toplumsallaşma sürecinin farklı aşamalarına odaklanır. İlk filmde tamamen yabancı ve çatışma halinde olduğu bir ortamın içinde yalnız misafir olan Recep, ikinci filmde patron sıfatı kazanarak düzenin bir parçası olur. Karakterin son filmde yaşadığı depresyon ise artık tanışmış olduğu tüketim toplumunun mutluluk, eğlenme ve haz alma buyruğunu (funmarality) ${ }^{49}$ akla getirir. Bu aşamalar içerisinde filmin bedensel güzellik ve çirkinliği ele alışına dair farklılıklar görülmektedir.

Filmin ana karakteri olan Recep bir maganda temsilidir. Maganda, zaman içerisinde yalnız bir karikatür tiplemesi olmaktan çıkmış ve cinsel açlığını sergileyen, cahil, kaba, kavgacı, etrafını rahatsız eden kişileri ötekileştirmek için kullanılan bir sıfat halini almıştır. Magandanın bedeni de tıpkı huyları gibi istenmeyen ve norm dışı olanı sergiler. Maganda kıllı bir vücuda sahip, iğrençliğinden tanınan, grotesk bir ucubedir. ${ }^{50}$ Güzel olmanın norm kabul edildiği bir kurgu içerisinde bir magandaya ancak çirkinlik yakışacaktır. Bununla tutarlı biçimde Recep İvedik de şişman, makyaj ile aşırı kıllı bir hale sokulmuş, mimik ve jestleri ile sıklıkla grotesk görünümlere bürünen bir karakterdir. Karakterin iriliği üzerine dar gelen kıyafetleri ve ona beyaz Türklerin dünyasında rehberlik eden (ilk filmde Belboy, ikinci filmde Ali Kerem, üçüncü filmde ise Zeynep) yardımcı oyuncuların minyonluğu ile vurgulanır. Recep'in bedeni çirkin olanı, istenmeyeni, ötekini temsil eder.

Recep İvedik'in yolda bulduğu cüzdanı sahibine teslim edip beş yıldızlı bir tatil köyünde misafir edilerek ödüllendirildiği, burada çocukluk aşkı Sibel ile karşılaşıp ona yeniden yakınlaşmaya çalıştığı ilk filmde ilginç olan, Recep'in karikatürize bedeninin anlatının gerçekliği içerisinde tamamen normal karşılanmasıdır. Recep diğer karakterlerden bedenine yönelik, komik ya da saldırgan, hiç bir olumsuz karşılık almaz. Bedeni kaynaklı olarak gülünç duruma düşmez ki bu irilik ve güçteki bir karakterin neye elini atsa kırmasını, nereye girse sıkışıklık yaratmasını beklemek çok da akıl dışı değildir. Oysa karakterin bedensel görünümü sıra dışı olsa da, anlatının gerçekliği içinde kabul gören, yadırganmayan bir profil ortaya koyar.

$\mathrm{Bu}$ filmde Recep'i istisnai kılan ne komedyen olması ne de ana karakter olmasıdır. Hangi karakterlerin bedensel görünümlerinin yadırganıp hangilerinin yadırganmadığına bakıldığında, erkek karakterlerin bedenlerinin büyük ölçüde görmezden gelindiğini, kadın karakterler sürekli olarak yaygın güzellik idealine uymayan niteliklerinden dolayı aşağılandığını görmek mümkündür. Recep'i bedeninin çirkinliğini bir baskı sebebi olarak omuzlarında taşımaktan kurtaran erkek olmasıdır. Sibel'in annesi "göbeğin düğüm düğüm olmuş, gerdanın pelikan gibi sarkmış" gibi yorumlara maruz kalırken otelde temizlik görevlisi olarak kadınlar "şişko patates, göbeğinin derisi gerilmiş davul gibi" sözler işitirler. Bu noktada ilginç olan bedensel görünümü ile ilgili olumsuz yorumlara maruz kalan kadınların, Recep'e tepki göstermek yerine kendi durumlarına üzülmeleridir. $\mathrm{Bu}$ şekilde yaygın güzellik idealine uymayan bedenlerin aşağılanması normal kabul edilir. Filmde Recep'in Sibel zannederek yanlışlıkla ilanı-1 aşk ettiği otel müşterisinin kilosu da sıklıkla vurgulanır; gülünç ve dehşet verici olarak kabul edilir. Müşteri oturduğu sandalyenin kırılmasına sebep olarak gülünç duruma düşer. Recep tarafından toynağa benzetilen ayaklarının yağlanarak ovulması yakın çekimde gösterilir. Kadının bedensel görünümü Recep'te dehşet uyandırır ve koşarak kaçmasına sebep olur. Recep'in ondan bahsederken sarf ettiği "Çirkin de bir şey", "Bayan diyorsunuz gelene bakın. Ben bunu kabul etmem" gibi ifadeler şişmanlık ile kadınlığın bağdaşmadığına işaret eder. O ancak "şey"dir.

Recep'in yaygın güzellik idealine uymayan kadınlar ile karşılaşmaları filmde güldürü unsuru olarak işlev görür. Yıkıcı bir pratik olarak gülme, gülünen kişiyi davranışını düzeltmeye zorlar. ${ }^{51}$ Bu bağlamda kadın çirkinliğine yönelen gülmenin normatif bir boyutu vardır. Anlatıda çirkinliğe atfedilen gülünç statüsünün, kendi başına çirkinliğin kendisinden değil, çirkin kabul edilen bireyin toplumla karşılaşmasından doğması ise dikkat çekicidir. Bergson'un uyumsuzluk kuramını akla getirir biçimde çirkinlik kendi başına komik olmaktan çıkar, normlar ile uyumsuz olduğu için komikleşir. Serinin ilk filminde gülme çirkin kişinin bunu onaylamayan başka kişiyle karşılaşmasından doğar.

Kadın karakterlerin maruz kaldığı alaya rağmen filmde yer alan hiç bir erkek, Recep ile kavga etse dahi fiziksel kusurlarından dolayı aşağılanmaz ya da gülünç duruma düşmez. Bu durumun tek istisnası Recep'in sonradan eşcinsel olduğunu öğrendiği bir kamyoncudur. Kamyoncunun Recep tarafından kilosuna istinaden "dombili" olarak adlandırılması ancak eşcinselliği ortaya çıktıktan sonra gerçekleşir. Kamyoncunun eşcinselliği onu geleneksel erkeklik modellerinin sınırlarından çıkartır ve bedenini eleştirilebilir hale getirir. Heteroseksüel erkeklerin her türlü bedensel görünüşünün normal karşılandığı bu kurgu içerisinde, Recep'in bedeninin komik 
ya da aşağı görülmemesini cinsiyetine bağlamak mümkündür. Karakterin bedeni yalnız diğer karakterler tarafından normal karşılanmakla ve gülünç durumlara sebebiyet vermemekle kalmaz, kendisi tarafindan da beğeni ile karşılanır. Filmde biri duşa girmeden önce, diğeri diskoya gitmeden önce olmak üzere iki kez ayna karşısında görülen Recep aynada gördüğü görüntüden memnundur. Ayna karşısında dans ederek soyunur, ayna karşısında şarkı söyler. Karakterin omuzlarını kabartarak dik yürüyüşü de özgüvenini göstermektedir.

Fatih özgüvenin sınıflandırmasına göre Türk sinemasında erkek şişmanlığının iki farklı yüzünü görmek mümkündür. Madalyonun bir yüzündeki şişman erkekler Masumiyet (2006) filmindeki Yusuf, Prensesin Uykusu'ndaki (2010) kütüphane memuru, Karanlıktakiler'deki (2009) Egemen, Korkuyorum Anne'deki (2004) Ali gibi mutsuz, "ezik" ve kırılganken, madalyonun diğer yüzünde kendi niteliklerini hiç önemsemeyen, saldırgan, Nurdan Gürbilekçi anlamıyla "ben de isterem kültürü" şişmanları vardır. ${ }^{52}$ Recep İvedik'in de aralarında bulunduğu bu ikinci grup 1980'lerde kuluçka sürecinde olan ve kısa sürede yaygınlık kazanan ideal beden kurgusuna, başka bir deyişle Beyaz Türklerin gülünç fitliğine, Kadir inanır gibi "taş" olmaya yönelen bir tepkidir. ${ }^{53}$ Ancak bu tepki yalnız erkek bedenini ideal beden kurgusundan azade kılmaya yöneliktir.

Filmde geleneksel erkeklik rollerinin sınırları içinde yer alan erkeklerin güzellikleri ya da çirkinlikleri tamamen önemsiz kabul edilirken kadın güzelliği ise cinsel çekicilikle bir tutulur. Güzel kadın bedenleri hem izleyicinin hem de karakterlerin seyrine sunulan bir arzu nesnesi ${ }^{54}$ işlevi görür. Recep Otele ilk geldiğinde tanga giymiş bir kadının kalçasına bakarken lobideki vazoyu devirir. Kamera bakışın hemen ardından kadının kalçasına yakın çekim yaparak izleyicinin de bakışı paylaşmasını sağlar. Recep havuz başına indiğinde güneşlenen kadınları seyreder. Recep'in çocukluk aşkı Sibel de yaygın güzellik idealine uygun bedeniyle seyircinin seyrine sunulur. Sibel'in demografik özellikleri, huyları, ilgi alanları anlatıda yer almaz. Dolayısı ile Sibel bir karakter olmaktan ziyade Recep'in aşık olduğu bir bedenden ibarettir. Karakter anlatı boyunca dar ve dekolte giysiler giyer ve anlatının gereklilikleri ile çelişse dahi, bedeni çerçeve içinde tutulur. Örneğin plajda Recep'e sıkıntılarını anlattığı sahne, duygusal bir sahne olmasına karşın yakın çekimler değil bel çekim kullanılmış, böylece kişisel bir ana uzaktan tanıklık etmek pahasına karakterin bikinili bedeni çerçeve içerisinde tutulmuştur.

Farklı sosyo-ekonomik statüdeki karakterlerin bedenleri yaygın güzellik idealine uygunluk bakımından değerlendirildiğinde ortaya çıkan manzara, tüketim toplumunun güzelliğe yüklediği prestij ve başarı yan anlamları ile uyumludur. Filmde yüksek-sosyo ekonomik statüye mensup olan müşterileri ${ }^{55}$ aynı zamanda genç, bakımlı ve formda bedenlere sahipken, düşük sosyo-ekonomik statüye mensup olan kamyoncular ve temizlik görevlileri genellikle bakımsız, şişman ve orta yaşlı görünmektedir.

Yaygın güzellik idealine uygun bedenleri övüp prestij, cinsel çekicilik ve seyredilme ile ilişkilendiren, uymayanları ise komik, dehşet verici ve aşağılanmayı hak eder biçimde ele alan ilk filmin bu tavrı, serinin ikinci filminde de devam etmektedir. Ancak bu sefer farklı olan erkeklerin de aynı güzel görünme zorunluluğundan nasibini almasıdır. Bunun nedenini ise, ilk filmde beyaz Türkler'in dünyasında yalnız bir ziyaretçi olan Recep'in, ikinci filmde patron sıfatı kazanarak bu dünyada bir yer edinmesi ile açıklamak mümkündür. Filmde Recep, ninesinin isteği üzerine iş bulmaya, toplumda saygınlık kazanmaya ve evlenmeye çalışır. Birkaç başarısız iş denemesinden sonra bir reklam ajansında patron olur,mesleki başarısı dolayısı ile dergi kapaklarına çıkacak kadar saygınlık kazanır fakat evlenmeyi başaramaz.

Uyum sağlamaya çalıştı̆̆ bu yeni dünyada artık Recep'in bedeni de gülünçtür. Üstelik komik ilk filmde olduğu gibi çirkin bedenin toplumla karşılaşmasından değil doğrudan karikatürize çirkinlikten ileri gelir. Önceki filmin uyumsuzluğa işaret eden tavrı bu kez kaybolmamakla birlikte azalır; çirkinliği izleyiciye teşhir etmek yeterli bir hal alır. Recep ninesinin evinde oturduğu koltuğa sığamaz, güçlükle oturup kalkar. Ninesinden kilosunu aşağılayan laflar işitir. Tüm kostümleri üzerine dar gelir, gömlek ve ceketlerinin ön düğmeleri hep gergindir. Host olduğunda giydiği yelek göbeğinin üzerine kalarak göbeğini vurgular. Yoga kursunda yere otururken yuvarlanır, kalkmak için başkasına tutunarak yardım alması gerekir. Recep dışında diğer erkek karakterlerin de bedensel görünüşleri alay konusu olur. Recep pizza kuryesi olarak çalışmaya başladığında promosyon pizzasını yediği erkek müşteri ile tartışır ki taşımakla mükellef olduğu yemeği yemesi şişmanlık ile iradesizlik arasındaki bağı vurgular. Müşteri şişmandır ve şişmanlığı açık renkli dar kıyafeti ile vurgulanır, yakın çekimlerden ziyade bel çekimde gösterilerek bedeni görünür kılınır. Bu tartışma esnasında Recep müşteriye "Ne yapacaksın lan tam pizzayı sen? Zaten yemişsin ayı gibi olmuşsun" ve "bu cimrilikle olmuşsun bin kilo" der. Bu sahnede hem Recep'in dayanamayıp servis etmekle mükellef olduğu pizzayı yemesi, hem de müşterinin şişmanlığının cimrilik ve bencillikle ilişkilendirilmesi, erkek şişmanlığı bile belirli davranış kalıpları arasında bağ kurar ve şişmanlığı erkeğe atfedilen rasyonel olma gerekliliği ile çelişkisini ortaya koyar. Recep 
pizzacıdaki patronunun keline tokat atar, ödül töreninde başka bir erkeğin peruğundan korkar. Reklam ajansında başka bir erkek çalışanını uzun saçlı olduğu için azarlar.

Serinin ikinci filminde kadın şişmanlığının kabul edilemez olduğu algısı devam eder. Recep kasiyerlik yaparken cips alan kadın müşterisini "bak bunlar hep kilo" diyerek uyarır. Müşteri Recep'e hak verir. Recep eczanede kalfa olarak çalışmaya başladığında ise eczaneye gelen kilolu bir kadına fitilin nasıl kullanılacağını anlatmak ister. Kadının kalçaların el hareketleri ile canlandırarak "İki tane yanak var böyle kocaman. Normal insanda ufak olur." cümlesini kurar ve böylece şişmanlığın kesinlikle normal olmadığı bir kez daha vurgulanır. Recep internet üzerinden tanıştığı bir kadınla Uzak Doğu restoranında buluştuğunda ilk yorumları yine kadının görünüşe yöneliktir. Diğer örneklerden farklı olarak bu kez yaşlılık, şişmanlık, irilik ya da minyonluk söz konusu değildir fakat abartılı bir makyaj ve gündelik hayatta kullanılmayacak bir saç ve kostüm söz konusudur. Recep muhattabını arabaya benzeterek "kaportasının" çürük olduğundan söz eder. "Ruh güzelliğin iyidir,onu bilmem. Gel gelelim ruhlar aleminde de yaşamıyoruz. O yüzden dış güzelliğine önem veririm yani ben kadında" diyerek aşk ve/veya evlilik için kadın güzelliğinin önemini doğrudan dile getirir.Bir kadının nasıl görünmesi gerektiği ile ilgili katı tutumu yoga sınıfında da kısa saçlı kadınları erkek zannetmesi ile kendisini gösterir.

İdeal beden kurgusunun çirkinliğin aşağılanması ve gülünç durumlara yol açması üzerinden kurulduğu filmde güzellik nadiren söz konusu olur. Erkek güzelliğine dair herhangi bir referansa rastlanmazken kadın güzelliği yine erkekler tarafından arzulanır olmakla bir tutulur. Recep'in fal bakarak yakınlaşmaya çalıştığı reklam ajansı çalışanlarının tamamı yaygın güzellik idealine uyumlu bedenlere sahiptir. Recep ajansın düzenlediği partide zayıf, uzun boylu ve bakımlı iki kadını ayrı ayrı taciz eder. Kadınlardan birine güzelliğini vurgulamak amacı ile "Miss İndia" şeklinde hitap eder. Bu filmde de güzellik yüksek sosyo-ekonomik statüdeki kişilere yakıştırılmıştır. Reklam ajansı çalışanları, yoga kursundakiler, Starbucks müşterileri ve uçak yolcuları genellikle yaygın güzellik idealine uygun bedenlere sahipken; Recep'in ninesi, ninesinin ölümünün ardından ziyarete gelen arkadaşları ve seyyar satıcılar genellikle yaşlı, kilolu ve bakımsızdır.

Serinin üçüncü filminde anlatının kronolojik olarak takip edilmediği anlaşılır. Recep yine işsizdir ve pek fazla arkadaşı yoktur. Depresyondadır. Kalacak yeri olmadığı için evinde misafir ettiği bir öğrenci olan Zeynep, hem Recep'e arkadaşlık eder hem de keyif alabileceği hobiler bulmasına yardımcı olur. Bu filmde Recep yine etrafindakilerin bedensel görünüşleri ile dalga geçer. Ancak karakterin kendi bedeninden duyduğu hoşnutsuzluk ve kendi bedenine yönelik olarak diğer karakterlerden gördüğü baskı daha baskındır. Güzellik ise söz konusu edilmez. Bir zorunluluk olarak güzellik, çirkinliğin beraberinde getirdiği mutsuzluk üzerinden ortaya konur.

Film bir altın gününde dans eden, neredeyse tamamı kilolu ve orta yaşlı kadınlar ile açılır. Söz konusu sahnede kadınların bedenlerini yavaşlatılmış yakın çekimler ile gösterirken çerçevede sallanan göğüsler, dalgalanan kollar, el ile yenilen dolmalar vardır. Recep'in "pislik, şişman, gergedan gibi" şeklinde tanımladığı kadınlar filmin düşük sosyo-ekonomik statüdeki bireyleri algılayış biçimiyle tutarlı bir bedensel görünüme sahiptir. Recep kadınların tavsiyesi üzerine hocaya gittiğinde, bekleme salonundaki insan profillerinin de yine ağırlıklı olarak yaşlı, kilolu ve bakımsız olduğu görülür. Tam aksine psikologun bekleme salonundaki kişiler genç ve bakımlıdır. Ancak Recep buradaki bir hastanın ve sekreterin saçları ile dalga geçer. Bunun haricinde Recep'in bir başkasının fiziksel görünümüne yönelik olarak takındığı tek olumsuz tavır, kütüphanede sarf ettiği "bak hele optik" ve "saçlarının ortasını kazımışsın havaalanı gibi" sözcükleridir. Oysa filmde Recep'in bedeni hem diğer karakterlerden aldığı olumsuz tepkiler hem de izleyiciye komik sunulma bakımından çok daha baskı altındadır.

Recep'in bedensel görünümünün komik bir olaya yol açtığı ilk sahne, ava giden arkadaşları ile birlikte ormana gittiği sahnedir. Burada arkadaşları Recep'i çalıların arasında görür ve cüssesinden dolayı ayı zanneder. Recep vurulur ve bu kez kaldırıldığı hastanede doktor tarafından kendisiyle dalga geçilir. Doktor karakterin kalçası çok geniş olduğu için tüm saçmaları tek lobuyla "yakalamış" olmasına güler. Recep'in evde tek başına nasıl zaman geçirdiğini anlatan sahnelerde karakterin bedeni grotesk biçimlere gider. Lekeli kıyafetler içinde, yemek artıkları arasında yuvarlanır ve iğrenç görünür. Zeynep ile tanıştıktan sonra kendi bedeninden duyduğu hoşnutsuzluk belirginleşir. Zeynep'in "Göbek olmuş fiçı gibi, bütün gün evde oturuyorsun" şeklindeki eleştirisine istinaden gittikleri karate kursunda bu kez karate hocası Recep'e "turşu fiçısı", "dombili" gibi hitaplarda bulunur. Zeynep'in bir arkadaşı ona "amca" dediğinde, onu gençliğin sınırlarından çıkartan bu hitap çekline çok sinirlenir. Tiyatro, flüt kursu, paintball gibi birkaç farklı denemenin ardından aradığını bulamayan Recep, genlerinden dert yanar. "Ben aslında anama babama kızıyorum. Madem genetik yapınız bozuk arkadaş (...) o zaman beni neden dünyada bıraktırıyorsun ya. (...) derdin, kederin içine atıyorsun beni bu bedenle." 
cümlesi ile başlayan serzenişinin ardından annesinin bıyıklı olduğunu, bir hayvanat bahçesi gezisinde arkadaşlarının babasını orangutan zannettiğini anlatır. Son çare olarak, mutlu olmak için kuaföre gider. Zeynep'in metroseksüel kuaförü, farklı bir güzellik anlayışının temsilcisi olarak, sarıya boyadığı saçları ile Recep'i daha da mutsuz eder. Film çözümün arkadaşlık ilişkilerinde olduğuna işaret ederek sona erse de, Recep'in mutsuzluğunda bedensel görünüşünün payı olduğu anlatı boyunca hissedilir.

\section{Sonuç}

Formda bir beden, gençlik ve bakımlılı̆̆ bir norm haline getiren, bu norma uyanları arzulanma, cinsel çekicilik ve prestijle ödüllendirip uymayanları çirkinlik ile yaftalayarak sözel yolla ve gülünçleştirme ile aşağılayan ideal beden kurgusunu Recep İvedik serisinde açıkça görmek mümkündür. Seride yaygın güzellik idealine uyan ve uymayan bedenlere atfedilen anlamlar, tüketim toplumunun ideal beden kurgusunu yansitmaktadır. Bedenin işlevselliği ile değil, değişim değerini veren yan anlamları ile değer bulduğu bu kurguda güzellik prestije işaret etmektedir ki filmde bu algı yüksek sosyo-ekonomik statüdeki kişilerin güzelliği ve düşük sosyo-ekonomik statüdeki kişilerin çirkinliği şeklinde kendini göstermektedir. Tüketim toplumuna entegre olmuş bir toplumsal grup olan Beyaz Türkler güzelliğin de taşıyıcısıdır.

Bir magandanın bedenine, yani istenmeyen ve ötekileştirilenlerin toplandığı bir bedene sahip olan Recep, henüz Beyaz Türklerin arasında misafir olduğu ilk filmde bedensel görünüşünden memnundur. Misafirlik sürecinde güzellik yalnız kadınlar için bir zorunluluktur. Ancak Recep'in patron sıfatı kazanarak bu dünyanın bir parçası olduğu ikinci filmde, yaygın güzellik ideali hem kadınların hem de erkeklerin nasıl görünmesi gerektiğini belirler. Kadın olmak için kadın gibi görünmenin, yani zayıf, bakımlı ve genç olmanın bir zorunluluk olarak sunulduğu ilk iki filmin ardından üçüncü film tamamen Recep'e odaklanır. Recep'in mutsuz, bıkmış, melankolik halinde bedensel görünüşünün payı olduğu film boyunca hissettirilir. Seri boyunca güzellik bir zorunluluk olarak ele alınır ve bu zorunluluğa uymayan bedenler aşağılanarak ve gülünç kılınarak norm dişına itilir.

Katı sınırları olan, tek tip bir yaygın güzellik idealinin kişilerin hayatlarını bu denli etkilediği bir anlatının, sinemada çok sayıda izleyiciye ulaşmış olması endişe vericidir. Recep İvedik serisinde yeniden üretilip pekiştirilen bu anlamlar kapitalist ekonominin ve patriarkinin çıkarlarına hizmet ederken, bireyler üzerinde karşılık verilmemesi mutsuzluğa yol açan bir baskı oluşturmaktadır. Bu konuya yönelik hassasiyet göstermeyen, dahası bu algıyı anlatısının işleyişinde merkezi bir role koyan Recep İvedik gibi filmler, yaygın güzellik ideali buyruğunun olumsuz sonuçlarının sorumluluğu paylaşmaktadır. 
${ }^{1}$ Wes Gebring karakter komedisinin üç ana bileşenini gezgin karakter, fiziksel komedi eğilimi, karakterin mazlumluğu ya da yetersizliği şeklinde belirlemiştir. WesGebring, "Comedy," SchirmerEncnyclopedia of Film Vol. 1 ed.Barry Keith Grant (Detroit: Thompson Gale, 2007), 354.

${ }^{2}$ Michel Foucault, Cinselliğin Tarihi (İstanbul: Ayrınt1, 2012), 70.

${ }^{3}$ Jean Baudrillard, Tüketim Toplumu: Söylenceleri/Yapıları (İstanbul: Ayrınt1, 2012), 81.

${ }^{4}$ Baudrillard, Tüketim Toplumu, 150.

${ }^{5}$ Baudrillard, Tüketim Toplumu, 153.

${ }^{6}$ Baudrillard, Tüketim Toplumu, 75.

${ }^{7}$ Meltem Ahıska ve Zafer Yenal, Aradığınız Kişiye Şu Anda Ulaşılamıyor: Türkiye'de Hayat Tarzı Temsilleri 1980-2005 (İstanbul: Osmanlı Bankası, 2006), 8-14

${ }^{8}$ Nurdan Gürbilek, Vitrinde Yaşamak (İstanbul: Metis, 2011), 29.

${ }^{9}$ Ahıska ve Yenal, Aradı̆̆ınız Kişiye Şu Anda Ulaşılamıyor, 8.

${ }^{10}$ Ayşe Düzkan, "Moralim Bozuldu Kuaföre Gittim," Bedende Kıpırdanmalar ed. Gülnur Elçik ve Tuğba B. Özenç (İstanbul: Varlk, 2010), 103

${ }^{11}$ Ayşe Düzkan, "Moralim Bozuldu Kuaföre Gittim," 102.

${ }^{12}$ Cash Barbara ve Louis'in 3000 katılımcı ile gerçekleştirdiği araştırmaya göre bedeninden memnun olmayan kadın sayısı bedeninden memnun olmayan erkek sayısından \%14 fazladır. Gülnur Elçik "Paramparça Bedenler ve Lanetli Şişmanlık" Bedende Kıpırdanmalar ed. Gülnur Elçik ve Tuğba B. Özenç (İstanbul: Varlık, 2010), 141

${ }^{13}$ Bedenden hoşnutsuz olma kaynaklı depresyon kadınlarda erkeklerin iki katı sıklığında görülmektedir. Gülnur Elçik "Paramparça Bedenler ve Lanetli Şişmanlık," ed. Gülnur Elçik ve Tuğba B. Özenç Bedende Kıpırdanmalar (İstanbul: Varlık, 2010 ), 141.

${ }^{14}$ Ayşe Düzkan "Moralim Bozuldu Kuaföre Gittim", 104.

${ }^{15}$ Susan Bordo, Unbearable Weight: Feminism, Western Culture and the Body (Berkeley: University of California, 1995$), 3$.

${ }^{16}$ Susan Bordo, Unbearable Weight: Feminism, Western Culture and the Body, 5-15.

${ }^{17}$ Fatih Çakı, "Batı Dışı Toplumlarda Gençlik ve Beden İmajı" Beden Sosyolojisi ed. Kadir Canatan (İstanbul: Açılım, 2011 ), 309.

${ }^{18}$ Ayşe Düzkan, "Moralim Bozuldu Kuaföre Gittim," 101.

${ }^{19}$ İnci User "Biyoteknolojiler ve Kadın Bedeni," Dişilik Güzellik ve Şiddet Sarmalında Kadın ve Bedeni ed. Yasemin İnceoğlu ve Altan Kar (İstanbul: Ayrint1, 2010), 97.

${ }^{20}$ John Berger, Görme Biçimleri (İstanbul: Metis, 2011), 47.

${ }^{21}$ İnceoğlu ve Kar, "Yeni Güzellik ikonları: İnsan Bedeninin Özgürlüğü mü, Mahkumiyeti mi?" Dişilik Güzellik ve Şiddet Sarmalında Kadın ve Bedeni ed. Yasemin İnceoğlu ve Altan Kar (İstanbul: Ayrınt1, 2010), 76.

${ }^{22}$ İnceoğlu ve Kar,"Yeni Güzellik ikonları." 72.

${ }^{23}$ Umberto Eco, güzelliğin tarafsız bir değer takdiri olduğunu ve bu nedenle tanımlanmasının güç olduğunu dile getirmiş, fakat çirkinliğin her zaman uyandırdığı tiksintiden tespit edilebileceğini savunmuştur. Umberto Eco, Çirkinliğin Tarihi (İstanbul: Doğan Kitap, 2009), 19.

${ }^{24}$ Susan Bordo, "Hunger as Ideology" Ways of Reading An Antholgy for Writers ed. David Bartholomae ve Anthony Petrosky. (Boston: Bedford/ St. Martins, 2002), 155-156.

${ }^{25}$ Gülnur Elçik, "Paramparça Bedenler ve Lanetli Şişmanlık",141-142.

${ }^{26}$ Gülnur Elçik, "Paramparça Bedenler ve Lanetli Şişmanlık",141-142.

${ }^{27}$ Serpil Sancar, Erkeklik Imkansız İktidar: Ailede Piyasada ve Sokakta Erkekler (İstanbul: Metis 2011), 303.

${ }^{28}$ Elif Gazioğlu, "Yaşl1lık, Ah! O Sefil Vücut" Bedende Kıpırdanmalar ed. Gülnur Elçik ve Tuğba B. Özenç (İstanbul: Varlk, 2010), 116.

${ }^{29}$ Gürsel Yaktıl Oğuz, "Güzellik Kadınlar İçin Nasıl Vaade Dönüşür: Kadın Dergilerindeki Kozmetik Reklamları Üzerine Bir Deneme" Selçuk İletişim, no. 4 (2010): 190- 191.

${ }^{30}$ Sencer Ayata, "Yeni Orta Sınıf ve Uydu Kent Yaşamı," Kültür Fragmanları: Türkiye'de Gündelik Hayat ed. Deniz Kandiyoti ve Ayşe Saktanber (istanbul: Metis, 2010), 53.

${ }^{31}$ Gülten Uçan, "Post-modern Erkeklik," Celal Bayar Üniversitesi Sosyal Bilimler Dergisi 2, no. 10 (2012): 269.

${ }^{32}$ Gülten Uçan, "Post-modern Erkeklik," 268.

${ }^{33}$ Gülnur Elçik, "Paramparça Bedenler ve Lanetli Şişmanlık", 151.

${ }^{34}$ Pacher'dan Aktaran Mike Featherstone, "The Body in Consumer Culture", The Body: Social Process and Cultural Theory, ed. Mike Featherstone, Bryan S. Turner (London: Sage, 1991), 178.

${ }^{35}$ Stephen M. Smith, William D. Mcntosh ve Doris G. Bazzni "Are Beautiful Good İn Hollywood? An Investigation of the Beautyand-Goodness Steteotype on Film" Basic And Applied Social Psychology 1, no. 21 (1999) 69-80.

${ }^{36}$ Smith, Mcntosh ve Bazzni, "Are Beautiful Good in Hollywood?", 70-75

${ }^{37}$ Gregory Fouts ve Kimberley Burgaff, "Television Situation Comedies: Female Body Images and Verbal Reinforcements" Sex Roles, no. 40 (1999): 474.

${ }^{38}$ Gregory Fouts ve Kimberley Burgaff "Television Situation Comedies: Female Weight, Male Negative Comments and Audience Reactions" Sex Roles no. 42 (2000): 927.

${ }^{39}$ Gregory Fouts ve Kimberley Burgaff, "Television Situation Comedies", 927.

${ }^{40}$ Henri Berson Gülme: Komiğin Anlamı Üzerine Bir Deneme (İstanbul: Ayrınt1, 2006), 11.

${ }^{41}$ Henri Bergson, Gülme: Komiğin Anlamı Üzerine Bir Deneme (İstanbul: Ayrıntı, 2006).

${ }^{42}$ Sigmund Freud Espriler ve Bilinçdış1 ile İlişkileri (İstanbul: Payel, 2012). 
${ }^{43}$ Thomas Hobbes'dan aktaran Michael Billing, Laughter and Ridicule: Towards a Social Critique of Humour (Notthingam: Sage, 2005), 50-53.

${ }^{44}$ Stephen Wagg, "Comedians and Politics" I Tell a Joke or Two: Comedy Politics and Social Differences ed. Stephen Wagg (londn: Routledge 1998), 268.

${ }^{45}$ Mike Featherstone, "The Body in Consumer Culture" 172, 175.

${ }^{46}$ Poul McDonald, The Star System: Hollywoods Production of Popular Identities (london: Wallflower, 2005), 5.

${ }^{47}$ Dilek İmançer, Pınar Ö. Bilis, Mehmet Yılmaz "Medyada İmajiner Kimliğin Kurulma Biçimleri: Bir Model Olarak Yıldız Olgusu". Selçuk Iletişsim Dergisi. no. 3 (2006) 111-115.

${ }^{48}$ Örneğin bireyin bir rock yıldızınının hayranı olduğunu belirtmesi, ya da bir mafya dizisinin yıldızından hiç hoşlanmadığını belirtmesi hem bireyin aidiyet grubunu, kimliğini oluşturur hem de yıldızı rol modeli olarak konumlar. Komedyenlerin personaları da bu noktada yıldızların otantik kimlikleri ile benzer bir işlev görmektedir.

${ }^{49}$ Baudrillard Tüketim Toplumu, 86.

${ }^{50}$ Ayşe Öncü, "1990'larda Küresel Tüketim, Cinselliğin Sergilenmesi ve İstanbul'un Küresel Haritasının Yeniden Biçimlenmesi" Kültür Fragmanlarl: Türkiye'de Gündelik Hayat ed. Deniz Kandiyoti ve Ayşe Saktanber (istanbul: Metis, 2010), 191.

${ }^{51}$ Henri Bergson, Gülme, Komiğin Anlamı Üzerine Bir Deneme, 17-18.

${ }^{52}$ Fatih Özgüven "Tombulların Belirişi" Bir Kapıdan Gireceksin ed. Umut Tümay Aslan (İstanbul: Metis, 2012), 100-102

${ }^{53}$ Fatih Özgüven, "Tombulların Belirişi" 99.

${ }^{54}$ Laura Mulvey, "Görsel haz ve Anlatı Sineması" 25. Kare no. 21 (1997):42.

${ }^{55}$ Tatil köyünde Yalnız Sibel'in annesi ve Recep'e aşık olan kadın şişmandır. Deniz ve havuz kenarındaki bütün kişiler genç ve formda bedenlere sahipken, kilolu olarak tanımlanabilecek üç figüran yalnız otelin yemek hanesinde görülmüştür. 


\section{Kaynakça}

Ahıska, Meltem ve Zafer Yenal Aradı̆̆ınız Kişiye Şu Anda Ulaşılamıyor: Türkiye'de Hayat Tarzı Temsilleri 1980-2005 (İstanbul: Osmanlı Bankası, 2006)

Ayata, Sencer. "Yeni Orta Sınıf ve Uydu Kent Yaşamı" Kültür Fragmanlarl: Türkiye'de Gündelik Hayat ed. Deniz Kandiyoti ve Ayşe $\quad$ Saktanber (İstanbul: Metis, 2010)

Baudrillard, Jean. Tüketim Toplumu: Söylenceleri/Yapıları (İstanbul: Ayrıntı, 2012)

Berger, John. Görme Biçimleri (İstanbul: Metis, 2011)

Berson, Henri Gülme: Komiğin Anlamı Üzerine Bir Deneme (İstanbul: Ayrıntı, 2006)

Billing, Michael. Laughter and Ridicule: Towards a Social Critique of Humour (Notthingam: Sage, 2005)

Bordo, Susan. Unbearable Weight: Feminism, Western Culture and the Body (Berkeley: University of California, 1995)

Bordo, Susan. "Hunger as Ideology" Ways of Reading An Antholgy for Writers ed. David Bartholomae ve Anthony Petrosky. (Boston: Bedford/ St. Martins, 2002)

Çakı, Fatih. "Batı Dışı Toplumlarda Gençlik ve Beden İmajı" Beden Sosyolojisi ed. Kadir Canatan (İstanbul: Açılım, 2011)

Düzkan, Ayşe. "Moralim Bozuldu Kuaföre Gittim," Bedende Kıpırdanmalar ed. Gülnur Elçik ve Tuğba B. Özenç (İstanbul: Varlık, 2010)

Eco, Umberto. Çirkinliğin Tarihi (İstanbul: Doğan Kitap, 2009)

Elçik, Gülnur ve Tuğba B. Özenç. Bedende Kıpırdanmalar (İstanbul: Varlık, 2010)

Elçik, Gülnur. "Paramparça Bedenler ve Lanetli Şişmanlık" Bedende Kıpırdanmalar ed. Gülnur Elçik ve Tuğba B. Özenç (İstanbul: Varlik, 2010).

Featherstone, Mike. "The Body in Consumer Culture", The Body: Social Process and Cultural Theory, ed. Mike Featherstone, Bryan S. Turner (London: Sage, 1991), 178

Freud, Sigmund. Espriler ve Bilinçdışı ile İlişkileri (İstanbul: Payel, 2012)

Foucault, Michel. Cinselliğin Tarihi (İstanbul: Ayrıntı, 2012)

Fouts, Gregory ve Kimberley Burgaff, "Television Situation Comedies: Female Body Images and Verbal Reinforcements" Sex Roles, no. 40 (1999): 473-481

Fouts, Gregory ve Kimberley Burgaff "Television Situation Comedies: Female Weight, Male Negative Comments and Audience Reactions" Sex Roles no. 42 (2000): 925-932

Gazioğlu, Elif. "Yaşlılık, Ah! O Sefil Vücut"Bedende Kıpırdanmalar ed. Gülnur Elçik ve Tuğba B. Özenç (İstanbul: Varlık, 2010)

Gebring, Wes. "Comedy," SchirmerEncnyclopedia of Film Vol. 1 ed. BarryKeith Grant (Detroit: Thompson Gale, 2007)

Gürbilek, Nurdan. Vitrinde Yaşamak (İstanbul: Metis, 2011)

İmançer, Dilek., Pınar Ö. Bilis ve Mehmet Yılmaz "Medyada İmajiner Kimliğin Kurulma Biçimleri: Bir Model Olarak Yıldız Olgusu". Selçuk Illetişim Dergisi. no. 3 (2006)

İnceoğlu, Yasemin ve Altan Kar "Yeni Güzellik ikonları: İnsan Bedeninin Özgürlüğü mü, Mahkumiyeti mi?" Dişilik Güzellik ve Şiddet Sarmalında Kadın ve Bedeni ed. Yasemin İnceoğlu ve Altan Kar (İstanbul: Ayrınt1, 2010)

McDonald, Poul. The Star System: Hollywoods Production of Popular Identities (London: Wallflower, 2005)

Mulvey, Laura "Görsel haz ve Anlatı Sineması" 25. Kare no. 21 (1997): 38-46

Oğuz, Gürsel Yaktıl. "Güzellik Kadınlar İçin Nasıl Vaade Dönüşür: Kadın Derdilerindeki Kozmetik Reklamları Üzerine Bir Deneme" Selçuk İletişim, no. 4 (2010): 184-195 
Öncü, Ayşe. "1990'larda Küresel Tüketim, Cinselliğin Sergilenmesi ve İstanbul'un Küresel Haritasının Yeniden Biçimlenmesi" Kültür Fragmanlarl: Türkiye'de Gündelik Hayat ed. Deniz Kandiyoti ve Ayşe Saktanber (İstanbul: Metis, 2010

Özgüven, Fatih. "Tombulların Belirişi" Bir Kapıdan Gireceksin ed. Umut Tümay Aslan (İstanbul: Metis, 2012)

Sancar, Serpil. Erkeklik Imkansız İktidar: Ailede Piyasada ve Sokakta Erkekler (İstanbul: Metis, 2011)

Smith, Stephen M., William D. Mcntosh ve Doris G. Bazzni "Are Beautiful Good İn Hollywood? An Investigation of the Beautyand-Goodness Steteotype on Film" Basic And Applied Social Psychology. 1, no.21 (1999) 69-80.

Uçan, Gülten "Post-modern Erkeklik" Celal Bayar Üniversitesi Sosyal Bilimler Dergisi 2, no.10 (2012): 262-271.

User, İnci. "Biyoteknolojiler ve Kadın Bedeni," Dişilik Güzellik ve Şiddet Sarmalında Kadın ve Bedeni ed. Yasemin İnceoğlu ve Altan Kar (İstanbul: Ayrınt1, 2010) 